\section{Continuing Educational Needs and Preferences for Swiss Registered Dietitians: Lessons Learned}

\section{Abstract}

Bern University of Applied Sciences (BFH) in Switzerland offers continuing educational programs for registered dietitians. In order to initialize effective changes to maximize attendance, the promotors and barriers influencing the participation of Swiss registered dietitians to continuing education classes were identified. A survey was conducted from December 2013 to January 2014 and sent to 630 registered members of the Swiss Association of Registered Dietitians (SVDE). The questionnaire was developed on the web-based software Survey Monkey ${ }^{\circledR}$ and included 37 open- and closed-ended questions. Evaluation questions were based on a four-point Likert scale and space for individual comments was ensured. Data analysis included descriptive statistics and chi-squared tests. The final sample included 202 dietitians, the majority being female (96\%), between 25 and 54 years old (90\%) and $45 \%$ worked in clinical settings. Almost $70 \%$ had participated in a BFH continuing education course. Respondents were overall very satisfied with parameters including course registration, organisation, content, professional competence of teachers, and practical relevance. Preferred course format were short courses (1-2 days). The lecturer's limited practical experience, no interest to the subject matter, and no cost coverage by employer were mentioned as the main barriers for attending courses. Based on lessons learned from this evaluation, the following aspects should be considered in order to secure the attractiveness of such programs: Favouring shorter more intensive courses and having them taught by lecturers with a strong practical experience, and hence with more insightful approach. Topics should be established based on the audience's expectations and needs, possibly through an inquiry among professional societies. In addition, overlapping fields as for example nutritional psychology, gerontology, and transdisciplinary approaches could be further included to broaden the dietitians' perspectives and encourage a more holistic approach. Finally, the registration process and quality of teaching environment should be seamless, in order to avoid negative influences on the course.

Keywords: Continuing education; Dietetics; Nutritionists; Needs assessment

\section{Sadeghi L, Martins S, Müller S, Ruch L and Jenzer $\mathrm{H}$}

Health Division, R\&D Nutrition and Dietetics, Bern University of Applied Sciences, CH-3008 Bern, Switzerland

Corresponding author: Leila Sadeghi

$\equiv$ leila.sadeghi@bfh.ch

Health Division, R\&D Nutrition and Dietetics, Bern University of Applied Sciences, Murtenstrasse 10, CH-3008 Bern, Switzerland.

Tel: +41318483789

Fax: +41318483501

Citation: Sadeghi L, Martins S, Müller S, et al. Continuing Educational Needs and Preferences for Swiss Registered Dietitians: Lessons Learned. J Clin Nutr Diet. 2017, 3:1.

Received: January 30, 2017; Accepted: February 03, 2017; Published: February 10, 2017

\section{Introduction}

The profession of dietitian in Switzerland started with the establishment of the first school in Zurich in 1932 by two pioneers, Dr. med. W. Gloor from Cantonal Hospital Zürich and Dr. Otto Stiner from Zürich. The school of Bern was founded later on, in 1972. In the French-speaking part of Switzerland, the dietetics service of the Cantonal Hospital of Geneva was created in 1934.
In 1976, the school of dietetics in Geneva separated itself from the dietetics service of the Cantonal Hospital and education as well as functions of dietitians became more scientific. On a national level, the official professional association of dietitians (Berufsverband des Diätpersonals Schweiz (BDS)) was founded on April 21st 1942 with initially only about 20 members, and presided by M. Otth, Director from the school of Zürich, until 1946. 1982 is an important date for the profession, as the Swiss 
Red Cross provided recognition and regulation of the training, followed by the attribution of the title of graduated dietitian CRS at the national level, which was important for the recognition by insurance services. In 1984, the professional title was modified from Schweizerischer Verband der dipl. ERnährungsBeraterInnen (SVERB) to Schweizerischer Verband Dipl. Ernährungsberater/ innen (SVDE). On February 18th 1985, the school of Geneva was recognized by the Swiss Red Cross. Dietitians increasingly became powerful allies in the healthcare services.

At the beginning of the 21st century, the educational system changed from professional schools in Zurich, Geneva and Bern to courses offered at the Universities of Applied sciences in Geneva and Bern. As such, the profession of dietitians became academic. The first bachelor course in nutrition and dietetics at Bern University of Applied Sciences (Berner Fachhochschule (BFH)) was launched in 2007 [1,2].

Each year a cohort about 60 students starts the course of nutrition and dietetics at BFH. The whole education takes 3 years to complete, divided into 6 semesters followed by an additional practical module of 10 months [3]. As a remnant of the preacademic curriculum, one third of the education is completed in practice. The other two thirds are lectures in plenum or in seminars. The semesters consist of several modules and each year has a special focus. The first year concentrates on human health and the basics of communication and counseling, the second year on human diseases connected with nutrition and clinical work of dietitians. The last year prepares students for complex diagnoses and situations in their profession [3]. Upon completion of their studies, about $70 \%$ of the students will work in hospitals and clinics field [Unpublished results].

In 2013, the European Federation of the Associations of Dietitians (EFAD) published their Strategy for Lifelong Learning (SLL). The aim of the strategy was to promote the development of the dietetic profession on an academic, scientific and professional level and to support the self-development of dietitians, given that both should advance the status and reputation of the dietetic profession in Europe. Continuing Professional Development (CDP) can take place in several forms including work-based learning, self-directed learning, and evaluation of learning. The SLL should also ensure fulfilment of the professional code of ethics and good practice. However, no credit system exists so far which requests a minimum credit score to keep the academic title, nor is there a specialization for clinical, industrial or community services orientation. The function of EFAD is to support the national associations in order to accomplish this strategy [4,5].

Compared to European standards, the Dietitians Association of Australia (DAA) has gone one step further with their Accredited Practising Dietitian (APD) program. This program wants to ensure that all APDs take part in at least 30 hours of Continuing Professional Development (CPD) per year. Parts of the CPDs are to develop learning goals for each year and to be active in several modules, for example professional education or quality improvement activity. The "CPD-Cycle" is a good tool to reflect and evaluate each personal step [6]. To promote lifelong learning in Switzerland, BFH offers several continuing education programs in form of short courses, professional courses and CAS/MAS/DAS about different topics all throughout the year.

In a survey which analyzed the employment situation of dietitians with a BSc two years after their graduation, only $14 \%$ of dietitians stated that they enrolled in a continuing education course [Unpublished results]. In order to initialize targeted and effective changes to increase attendance, it is necessary to know the reasons underlying the lack of interest and to recognize needs and preferences of dietitians in terms of continuing education offers. The aim of this study was to illustrate the promotors and barriers for continuing education courses for Swiss dietitians. Promoting participation to continuing education programs to advance the profession on a scientific and professional level ensures the implementation of the Lifelong Learning Strategy of EFAD. This publication aims to share lessons learned from a Swiss continuing education program for registered dietitians.

\section{Material and Methods}

This study was led by the research team from Bern University of Applied Sciences (BFH), Health Division, applied R\&D in nutrition and dietetics. It was conducted as a cross-sectional, quantitative Web-based survey for registered dietitians, defined as authorized to freely execute the profession of dietitian and holding an undergraduate degree in Nutrition and Dietetics from an accredited school in Switzerland.

An invitation letter was sent by email to all German speaking registered members of the Swiss Association of Registered Dietitians (SVDE) and to dietitians holding a bachelor's degree of BFH, having graduated by latest 2013. The invitation letter included a link to the questionnaire. Participation was voluntary and anonymous.

The questionnaire was developed on the web-based software Survey Monkey ${ }^{\circledR}$. There were 37 questions in total, which were split into four sections: I) socio-demographic information, 2) previous participation to continuing education courses offered by $\mathrm{BFH}, 3$ ) previous participation to continuing education courses offered by other providers, and 4) preferences and suggestions to ameliorate the offer of continuing education in the field of nutrition and dietetics. The questionnaire consisted of open and closed questions. Evaluation questions were based on a four-point Likert scale (between 1-“Very satisfied" and 4-"Not satisfied"). Space for individual comments and feedbacks was ensured. A pilot-survey was sent to four dietitians who gave individual feedbacks on the questionnaire.

The answers were automatically saved in Survey Monkey ${ }^{\circledR}$. After two weeks, the participants received an e-mail reminder to fill out and submit the questionnaire. The data were analysed using IMB SPSS Statistics program (version 22 for Windows).

Descriptive analyses were performed and Chi-Square test was used to compare the relation between nominal variables.

\section{Results}

Of the approximately 630 registered dietitians contacted through the Swiss Dietetics Association, 202 completed and returned the 
questionnaire, for a response rate of $32 \%$. Data analyses were conducted on this sample of participants.

\section{Socio-demographic information}

The sample comprised a majority of women (96\%). $90 \%$ of participants were between 25 and 54 years old. Most participants attained a diploma HF (Höhere Fachschule) (37\%), the subsequent upgrade to the FH title (29\%) and a bachelor's degree (23\%). The HF certificate was the standard degree before the academic curriculum. A BSc degree can be obtained by these "HF" certified dietitians by further education for at least two years. Participants holding a Master's degree, or continuing education degrees such as CAS (certificate of advanced studies), DAS (diploma of advances studies), MAS (Masters of advanced studies) accounted for approximately $11 \%$ of the group. Forty-five percent of the participants were employed at a hospital or clinical setting, and nearly $28 \%$ worked in a dietetics practice (multiple answers possible). Thirty-five percent of the participants worked full-time (100\%) and the number of years of activity was evenly distributed among the dietitians between less than 5 years up to 20 or more years (Table 1).

\section{Participation and overall satisfaction rates}

Sixty-nine percent of respondents have participated in a BFH continuing education course for registered dietitians (Table 2). The majority of respondents seemed to be satisfied with the offers. Registration process, organizational aspects, quality of courses' content, lecturers' practical experience and practical relevance were overall very well-rated (Table 3). Specifically, concerning specialized courses offered by the BFH (5 ECTS), the majority of respondents were on average very satisfied to satisfied in terms of practical relevance (16\%, respectively $59 \%$ ), enrollment process ( $22 \%$, respectively $43 \%$ ), course organization ( $8 \%$, respectively $51 \%)$, quality of content $(23 \%$, respectively $43 \%)$ and lecturers' practical relevance/experience (31\%, respectively $38 \%)$. For the short courses as well, respondents were mainly either very satisfied or satisfied with the quality of content $(50 \%$, respectively $36 \%$ ), the course organization (36\%, respectively $54 \%$ ), the registration process (35\%, respectively $50 \%$ ), lecturers' practical relevance/experience $(58 \%$, respectively $35 \%)$ and practical relevance (37\%, respectively $43 \%$ ) (Table 4 ).

\section{Preferences for continuing education courses format and logistics}

Short courses (one to two days, without European Credit Transfer System (ECTS)) were selected as the preferred format, followed by specialized courses (worth 5 ECTS). The years of work experience as dietitian did not seem to influence the participants preferences for a specific course format $(p=0.6)$ (Table 5). In the survey, 68 respondents stated to have a preference for participating in a specialized course, compared to 140 respondents preferring the short courses format.

The majority of the respondents (86\%) selected newsletters (per E-Mail) as the preferred means for communication on upcoming

Table 1: Socio-demographic characteristics of respondents.

\begin{tabular}{|l|c|c|c|}
\hline 1 & \multicolumn{2}{|c|}{ N } & Percent (\%) \\
\hline $\begin{array}{l}\text { Gender } \\
\text { Female }\end{array}$ & 195 & 96 \\
\hline Male & 7 & 4 \\
\hline Total & 202 & 100 \\
\hline Age & & \\
\hline 24 or less & 6 & 3 \\
\hline 25 to 39 & 97 & 48 \\
\hline 40 to 54 & 84 & 42 \\
\hline 55 to 64 & 14 & 7 \\
\hline 65 or more & 1 & 0 \\
\hline Total & 202 & 100 \\
\hline Years of experience in dietetics & & \\
\hline Less than 5 & 50 & 25 \\
\hline 5 to 9 & 40 & 20 \\
\hline 10 to 19 & 50 & 25 \\
\hline 20 or more & 60 & 30 \\
\hline Total & 200 & 100 \\
\hline
\end{tabular}

$4 \quad$ Highest degree attained

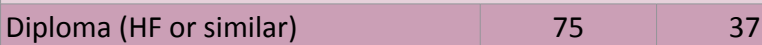

\begin{tabular}{|l|l|l|}
\hline Subsequent purchase of FH title & 59 & 29
\end{tabular}

$\begin{array}{lll}\text { Bachelor degree (BSC) } & 47 & 23\end{array}$

\begin{tabular}{|l|l|l|}
\hline Entry-level master & 10 & 5
\end{tabular}

Master degree (MSC)

Other (CAS, MAS, DAS)

Total

63

20

\begin{tabular}{c|c|}
\hline 5 & 3 \\
202 & 100
\end{tabular}

\section{Percent of workload (\%)}

15

\begin{tabular}{l|l}
\hline 40 & 37
\end{tabular}

60

80

34

100

44

Total

70

200

\section{$6 \quad$ Predominant work setting}

\begin{tabular}{|l|c|c|}
\hline Hospital/Clinic & 123 & 45 \\
\hline Nursing house & 9 & 3 \\
\hline Private practice & 77 & 28 \\
\hline Private economy/Industry & 19 & 7 \\
\hline Research & 4 & 1 \\
\hline Education System & 19 & 7 \\
\hline Non-profit Organization & 15 & 5 \\
\hline Other & 10 & 4 \\
\hline Total & 276 & 100 \\
\hline Main activity & & \\
\hline Team leader & 27 & 9 \\
\hline Independent work & 131 & 44 \\
\hline Supervisor & 35 & 12 \\
\hline Professor & 17 & 6 \\
\hline Scientific collaborator & 9 & 3 \\
\hline Administration & 20 & 7 \\
\hline Employees without specific function & 45 & 15 \\
\hline Other & 15 & 5 \\
\hline Total & 299 & 100 \\
\hline
\end{tabular}


Table 2: Participation in continuing education courses offered by BFH.

\begin{tabular}{|c|c|c|} 
& N & Percent (\%) \\
\hline & BFH participation & 69 \\
\hline Yes & 138 & 31 \\
\hline No & 61 & 100 \\
\hline
\end{tabular}

Table 3: Satisfaction with continuing education courses offered at BFH.

\begin{tabular}{|c|c|c|c|c|c|}
\hline & Very satisfied & Satisfied & Moderately satisfied & Not satisfied & Total N \\
\hline Enrollment process & $29(23 \%)$ & $70(54 \%)$ & $25(19 \%)$ & $5(4 \%)$ & 129 \\
\hline Course organization & $21(16 \%)$ & $80(62 \%)$ & $23(18 \%)$ & $5(4 \%)$ & 129 \\
\hline Quality of content & $32(25 \%)$ & $77(60 \%)$ & $18(14 \%)$ & $2(1 \%)$ & 129 \\
\hline Professional competence & $40(31 \%)$ & $73(56 \%)$ & $15(12 \%)$ & $2(1 \%)$ & 130 \\
\hline Practical relevance & $17(13 \%)$ & $79(62 \%)$ & $29(23 \%)$ & $2(2 \%)$ & 127 \\
\hline
\end{tabular}

Table 4: Satisfaction with specialized courses and short courses offered at BFH.

\begin{tabular}{|c|c|c|c|c|c|}
\hline & Very satisfied & Satisfied & Moderately satisfied & No satisfied & $\mathbf{N}$ \\
\hline \multicolumn{6}{|c|}{ Specialized courses } \\
\hline Enrollment process & $14(22 \%)$ & $27(43 \%)$ & $18(29 \%)$ & $4(6 \%)$ & 63 \\
\hline Course organization & $5(8 \%)$ & 31 (51\%) & $22(36 \%)$ & $3(5 \%)$ & 61 \\
\hline Quality of content & $14(23 \%)$ & $26(43 \%)$ & $19(31 \%)$ & $2(3 \%)$ & 61 \\
\hline Lecturers' practical relevance/experience & $19(31 \%)$ & $23(38 \%)$ & 19 (31\%) & $0(0 \%)$ & 61 \\
\hline Practical relevance & $10(16 \%)$ & 36 (59\%) & $14(23 \%)$ & $1(2 \%)$ & 61 \\
\hline \multicolumn{6}{|c|}{ Short courses } \\
\hline Enrollment process & $33(35 \%)$ & $48(50 \%)$ & $12(13 \%)$ & $2(2 \%)$ & 95 \\
\hline Course organization & $34(36 \%)$ & $51(54 \%)$ & $7(8 \%)$ & $2(2 \%)$ & 94 \\
\hline Quality of content & 47 (50\%) & $34(36 \%)$ & $11(12 \%)$ & $2(2 \%)$ & 94 \\
\hline Lecturers' practical relevance/experience & $54(58 \%)$ & $33(35 \%)$ & $5(5 \%)$ & $2(2 \%)$ & 94 \\
\hline Practical relevance & $35(37 \%)$ & $40(43 \%)$ & $17(18 \%)$ & $2(2 \%)$ & 94 \\
\hline
\end{tabular}

Table 5: Years of work experience as registered dietitians and perceived needs.

\begin{tabular}{|c|c|c|c|c|c|c|}
\hline & \multicolumn{5}{|c|}{ Years of work experience as dietitians } \\
\hline \\
\hline
\end{tabular}

continuing education courses (Table 6). Preferred days for attending continuing education were Thursdays and Fridays for $86 \%$ of respondents. For about $70 \%$ of respondents, courses should ideally last one full working day. Interestingly, $60 \%$ of respondents in the present study were not keen on exchanging thoughts with other colleagues within the scope of a continuing education course, as for instance in an online-forum (results not shown).

\section{Topics for the continuing education}

Questioned about priority topics for a CAS and for a specialized course, participants mainly mentioned metabolic diseases, diseases of the digestive system, obesity, and malnutrition. Besides other topics of interest, included food allergies and methodological skills. The latter topic hints at the increasing interest and involvement of dietitians in research projects. For short courses (1-2 days, without ECTS), the topics gastroenterology/visceral surgery and diabetes mellitus were prioritized (Tables 7 and 8). Other topics of interest included eating disorders, enteral/parenteral feeding and nutrigenomics. Nutrigenomics is currently being taught at BFH in both the Bachelor program in nutrition and dietetics and Master's program in Food Nutrition and Health (Stand 2016). 
Table 6: Preferences for continuing education format.

\begin{tabular}{|c|c|}
\hline & $\mathbf{N}$ \\
\hline \multicolumn{2}{|l|}{ Course type } \\
\hline Short course ( 1 or 2 days) & 140 \\
\hline Specialized course (5 ECTS) & 68 \\
\hline Lecture & 58 \\
\hline Seminar & 51 \\
\hline Workshop & 42 \\
\hline Diploma (MAS,DAS,CAS) & 37 \\
\hline Online course & 27 \\
\hline Other & 5 \\
\hline$N=163$ & \\
\hline \multicolumn{2}{|l|}{ Language } \\
\hline German & 163 \\
\hline English & 26 \\
\hline French & 10 \\
\hline Italian & 1 \\
\hline$N=163$ & \\
\hline \multicolumn{2}{|l|}{ Weekdays } \\
\hline Monday & 37 \\
\hline Tuesday & 53 \\
\hline Wednesday & 49 \\
\hline Thursday & 66 \\
\hline Friday & 72 \\
\hline Saturday & 42 \\
\hline Sunday & 11 \\
\hline No preference & 47 \\
\hline $\mathrm{N}=161$ & \\
\hline \multicolumn{2}{|l|}{ Length } \\
\hline Several weeks & 15 \\
\hline Multiple days & 89 \\
\hline Several evenings & 10 \\
\hline One day & 112 \\
\hline Half a day & 14 \\
\hline No preference & 20 \\
\hline Other & 9 \\
\hline$N=161$ & \\
\hline \multicolumn{2}{|l|}{ Time of day } \\
\hline Morning & 8 \\
\hline Afternoon & 13 \\
\hline Evening & 12 \\
\hline Whole day & 129 \\
\hline No preference & 30 \\
\hline $\mathrm{N}=161$ & \\
\hline \multicolumn{2}{|c|}{$\begin{array}{l}\text { Preferred communication means to announce continuing education } \\
\text { offer }\end{array}$} \\
\hline Newsletter (per E-mail) & 137 \\
\hline Flyer & 51 \\
\hline Online & 31 \\
\hline No preference & 9 \\
\hline Other & 5 \\
\hline
\end{tabular}

Table 7: Priority topics for continuing education as CAS and specialized courses.

\begin{tabular}{|c|c|c|c|}
\hline Metabolic disease & Priority 1 & Priority 2 & Priority 3 \\
\hline Disease of the digestive system & $29(19 \%)$ & $19(13 \%)$ & $15(13.2 \%)$ \\
\hline Malnutrition and underfeeding & $19(12 \%)$ & $18(12 \%)$ & $17(14.9 \%)$ \\
\hline Obesity & $19(12 \%)$ & $8(6 \%)$ & $17(14.9 \%)$ \\
\hline Malnutrition & $19(12 \%)$ & $18(12 \%)$ & $17(14.9 \%)$ \\
\hline Methodological skills & $15(10 \%)$ & $15(10 \%)$ & $12(10.5 \%)$ \\
\hline Food allergies & $12(8 \%)$ & $16(11 \%)$ & $7(6.1 \%)$ \\
\hline Kidney diseases & $5(3 \%)$ & $6(4 \%)$ & $2(1.8 \%)$ \\
\hline Leadership competencies & $5(3 \%)$ & $6(4 \%)$ & $11(9.6 \%)$ \\
\hline Social skills & $3(2 \%)$ & $6(4 \%)$ & $10(8.8 \%)$ \\
\hline Sequelae of overweight & $1(1 \%)$ & $6(4 \%)$ & $4(3.5 \%)$ \\
\hline Cardiovascular diseases & $0(0 \%)$ & $4(3 \%)$ & $4(3.5 \%)$ \\
\hline Total & $153(100 \%)$ & $146(100 \%)$ & $131(100 \%)$ \\
\hline
\end{tabular}

\section{Promotors and barriers to participation in continuing education courses}

The five most frequently mentioned reasons for taking continuing education courses were (multiple choices): personal interest/ desire (32\%), work-related or request from employer (15\%), professional requirement of permanent continuing education (15\%) and for title upgrade (14\%).

The most frequently cited reasons for not attending a continuing education course were (multiple choices): (lack of interest for) topics $(23 \%)$, high registration costs $(21 \%)$, other professional obligations $(10 \%)$ and travel time to course location (10\%). For $69 \%$ of respondents the course's costs were fully or partially covered by the employer (Table 9 ).

\section{Discussion}

The majority of the participants were female, which matches trends in this profession in Switzerland and worldwide. The years of work experience do not correlate with highest degree attained and it is worth to mention that the Master's degree in Food Nutrition and Health offered at the BFH was introduced in Switzerland in September 2015.

In general, participants seem to be satisfied with the continuing education courses offered by $\mathrm{BFH}$, with a strong preference for short courses, which last a day or two and are competitive partly due to lower registration costs compared with other CAS or credit earning specialized courses. This seems to be a major concern for those dietitians working in an own dietitian's office who have to finance educational activities fully themselves.

Short courses are also favored due to an easier logistic, such as taking less time off work and/or being financial (often partially) supported by employer. Besides logistics, the appeal of topics was on the top priority list for participants. 
Table 8: Priority topics for continuing education as short course.

\begin{tabular}{|c|c|c|c|}
\hline & Priority 1 & Priority 2 & Priority 3 \\
\hline $\begin{array}{c}\text { Gastroenterology/visceral } \\
\text { surgery }\end{array}$ & $19(13 \%)$ & $15(11 \%)$ & $10(8 \%)$ \\
\hline Diabetes mellitus & $18(12 \%)$ & 7 (5\%) & $4(3 \%)$ \\
\hline Eating disorders & $12(8 \%)$ & $19(14 \%)$ & $6(5 \%)$ \\
\hline Enteral/parenteral feeding & $12(8 \%)$ & $12(9 \%)$ & $10(8 \%)$ \\
\hline Childhood obesity & $9(6 \%)$ & $4(3 \%)$ & $3(2 \%)$ \\
\hline Psychiatry & $7(5 \%)$ & $9(6 \%)$ & $9(7 \%)$ \\
\hline Oncology & $6(4 \%)$ & $8(6 \%)$ & $8(6 \%)$ \\
\hline Obesity & $6(4 \%)$ & $6(4 \%)$ & $4(3 \%)$ \\
\hline Nutrigenomics & $6(4 \%)$ & $5(4 \%)$ & $14(11 \%)$ \\
\hline Geriatrics & $6(4 \%)$ & $5(4 \%)$ & $5(4 \%)$ \\
\hline Metabolic diseases & $6(4 \%)$ & $3(2 \%)$ & $6(5 \%)$ \\
\hline $\begin{array}{l}\text { Prevention/health } \\
\text { promotion }\end{array}$ & $6(4 \%)$ & $3(2 \%)$ & $3(2 \%)$ \\
\hline Food allergies & $5(3 \%)$ & $7(5 \%)$ & $4(3 \%)$ \\
\hline $\begin{array}{l}\text { Complementary/ } \\
\text { alternative medicine }\end{array}$ & $5(3 \%)$ & $7(5 \%)$ & $3(2 \%)$ \\
\hline Sport and nutrition & $4(2 \%)$ & $6(4 \%)$ & $10(8 \%)$ \\
\hline Pediatrics & $3(2 \%)$ & $3(2 \%)$ & $4(3 \%)$ \\
\hline Gynecology & $3(2 \%)$ & $1(1 \%)$ & $3(2 \%)$ \\
\hline Nephrology & $3(2 \%)$ & $3(2 \%)$ & $0(0 \%)$ \\
\hline Malnutrition & $2(2 \%)$ & $8(6 \%)$ & $5(4 \%)$ \\
\hline Research & $2(2 \%)$ & $4(3 \%)$ & $1(1 \%)$ \\
\hline Neurology & $2(2 \%)$ & $2(1 \%)$ & $6(5 \%)$ \\
\hline Cardiovascular diseases & $2(2 \%)$ & $1(1 \%)$ & $2(2 \%)$ \\
\hline Collective gastronomy & $2(2 \%)$ & $0(0 \%)$ & $5(4 \%)$ \\
\hline Pneumology & $0(0 \%)$ & $0(0 \%)$ & $2(2 \%)$ \\
\hline Total & $146(100 \%)$ & $138(100 \%)$ & $127(100 \%)$ \\
\hline
\end{tabular}

Interestingly, a majority of respondents in the present study were not keen on exchanging thoughts with their colleagues, as for instance in an online-forum (results not shown). One possible reason might be the competitiveness between practices, encouraging dietitians to keep their "knowledge" for themselves and stand out among peers. Moreover, there may be a lack of certainty when it comes to draw conclusions, as clinical and epidemiological studies in the field of human nutrition show so many times conflicting results. This absence of conclusiveness may lead to a tendency to not externalize personal thoughts on particular subjects. In addition, a possible fear of judgement from peers may discourage dietitians to freely exchange thoughts and point of views in a public setting (media, forums, congresses, etc.). One possible solution to increase the willingness to exchange between dietitians may be to encourage them to specialize in certain fields and not try to cover all health issues each by themselves so as to differentiate themselves from their colleagues and thus reduce this feeling of competitiveness. Novel topics should also be offered as continuing education options in order to broaden their knowledge perspectives and practical skills. Bridging the gap between traditional and more novel approaches, or alternative ones, should be further considered, for example, with the introduction to nutrigenomics, or with the combination of knowledge based on Western and Eastern medicine. Overlapping fields as for instance nutritional psychology, gerontology, and other trans-disciplinary options could be further included in the curriculum to encourage a more holistic approach to the dietetics field [7].

It is fairly probable that task shifting in public health will have a more sustainable impact on choice and offer of lifelong learning

Table 9: Promotors and barriers to participation in continuing education courses.

\begin{tabular}{|c|c|c|}
\hline \multicolumn{2}{|c|}{ Promotors for attending continuing education } \\
\hline $\begin{array}{c}\text { Personal interest } \\
\text { For the subsequent } \\
\text { acquisition of FH title }\end{array}$ & 111 & - \\
\hline $\begin{array}{c}\text { By employer request } \\
\text { Obligation for permanent } \\
\text { education }\end{array}$ & 48 & - \\
\hline $\begin{array}{c}\text { Acquisition of additional } \\
\text { qualifications for the current } \\
\text { field of employment }\end{array}$ & 52 & - \\
\hline $\begin{array}{c}\text { Preparing for change to } \\
\text { another field of employment }\end{array}$ & 44 & - \\
\hline $\begin{array}{c}\text { Career opportunities } \\
\text { Improve opportunities of } \\
\text { labor market }\end{array}$ & 7 & - \\
\hline Higher salary income & 14 & - \\
\hline Scientific carrier & 1 \\
\hline Other & 3 \\
\hline Total & 10 & - \\
\hline Barriers for not attending & 350 \\
\hline
\end{tabular}

Barriers for not attending continuing education

Topics of the course 31

Lack of information about

further education

Professional obligation

3

Lack of support from the employer

Costs for further education 29

Expenditure of time

Travel time

Cost for the travel

Private stuffs

31

egative feedback from others

Other

Total

13

9

3

8

9

\begin{tabular}{|c|c|}
\hline others & 5 \\
\hline Other & 15 \\
\hline
\end{tabular}

\section{Coverage of costs through employer}

\begin{tabular}{|c|c|c|}
\hline Yes & 39 & 30 \\
\hline Partially & 51 & 39 \\
\hline No & 40 & 31 \\
\hline Total & 130 & 100 \\
\hline
\end{tabular}

Did the course correspond to your expectations?

\begin{tabular}{|c|c|c|}
\hline Yes & 75 & 62 \\
\hline Partially & 42 & 35 \\
\hline No & 3 & 3 \\
\hline Total & 120 & 100 \\
\hline
\end{tabular}

Would you visit again and/or recommend it to a colleague?

\begin{tabular}{|c|c|c|}
\hline Yes & 111 & 92 \\
\hline No & 10 & 8 \\
\hline Total & 121 & 100 \\
\hline
\end{tabular}


topics [8], as dietitians acquire new responsibilities and are confronted with novel approaches in their practice. In addition, upcoming credit systems requiring a minimal lifelong learning activity might change the personal interest behavior towards a task- and responsibility- dependent planning of how to keep up with future scientific challenges. It might be interesting to seek dialogue with countries such Australia which has as well an established system and learn from respective experiences to find optimal solutions for the complex issue of implementing continuing education. On one side, exchanges on experiences in terms of continuing education programs might be very helpful to refine and re-design further ones, while acquiring novel insights into other countries' taught fields would shed light on new specialization domains that were not considered before.

From this point of view, it is not yet convincing and evident as to whether dietitians have really performed the step to an academic profession. On one side, this includes an interest to acquire theoretical basics besides and beyond flow-chart-like guidelines or procedures for daily work. In addition, it is important to value individual practical experiences of the continuing education participants, and not to neglect this aspect in the curriculum [7]. Experiences "from the field" may prove to be as much enriching as theoretical knowledge and lead to critical evaluations and worthwhile exchanges on a particular topic.

\section{Conclusion}

In order to secure the attractiveness of continuing education courses for dietitians, special consideration should be paid to the following aspects: a smooth registration process/organization, as well as attractive course costs and appealing topics with good quality content, and a strong practical orientation. Practical relevance and competence of the lecturers is highly recommended. It is arguable if, considering that most participants are satisfied with their experiences and the participants' quota has not yet reached its full potential, the information about the courses reaches optimally the potential participants. It may be necessary to further look at marketing and advertisement strategies. Dietitians will have to recognize and accept a comprehensive responsibility in multi-disciplinary managed care, for which academic behavior will be compulsory. Dietary practice is evolving very quickly and continuing education in this field needs to rely on more than just itself. With nowadays increasing value given to transdisciplinary work, novel aspects and adjacent fields bound to human nutrition should be further considered in the curriculum [7]. Promoting experience-based knowledge next to theoretical frameworks and empirical evidence would be the next step.

\section{Acknowledgement}

The authors would like to acknowledge the support of Carmen Forrer, Gabi Fontana, Valérie Bächli, and Marta Silva in this project, as well as Josiane Brun and Núria Rubio Petit for their review work. 


\section{References}

1 Girod, Véronique (2010) Stratégies de professionnalisation des diététiciennes: analyse de contenu des articles d'une revue professionnelle de 1996 à 2006.

2 http://www.svde-asdd.ch/wp-content/uploads/2016/11/ SVERB_50-Jahre_D_ganz.pdf

3 Fachhochschule B (2016): Bachelor in Ernährung und Diätetik. Studium und Beruf.

4 http://www.codnib.es/attachments/article/455/EFAD_Lifelong_ Learning_Strategy_.pdf
5 http://www.efad.org/downloadattachment/4176/7242/DIETS2Guide-Toolkit-LLL-2013-1.pdf

6 http://daa.asn.au/wp-content/uploads/2011/03/APD-GuideOCT-2016.pdf

7 Gingras J, Asada Y, Fox A, Coveney J, Berenbaum S, et al. (2014) Critical Dietetics: A discussion paper. J Crit Dietetics 2: 2-12.

8 Jenzer H, Sadeghi L (2016) Development of curricula in nutrition and dietetics-Pharmacology fills gaps, creates clarity and brings added value. In Aktuel Ernahrungsmed 41: 103-112. 